\title{
Assessing the Optimality of a COVID Lockdown in the United States
}

\section{Anna Scherbina ${ }^{1}$ (D)}

Received: 15 January 2021 / Accepted: 18 February 2021 / Published online: 8 May 2021

(C) The Author(s), under exclusive licence to Springer Nature Switzerland AG 2021

\begin{abstract}
Though COVID vaccines have been available since December 2020, the rate at which they are administered remains slow, and in the meantime the pandemic continues to claim about as many lives every day as the $9 / 11$ tragedy. I estimate that with the promised rate of vaccinations, if no additional non-pharmaceutical interventions are implemented, 203 thousand additional lives will be lost and the future cost of the pandemic will reach $\$ 1.3$ trillion, or $6 \%$ of GDP. Using a cost-benefit analysis, I assess whether it is optimal for the United States to follow the lead of many European countries and introduce a nation-wide lockdown. I find that a lockdown would be indeed optimal and, depending on the assumptions, it should last between two and four weeks and will generate a net benefit of up to $\$ 653$ billion.
\end{abstract}

Keywords COVID-19 · Pandemic curve · Cost-benefit analysis ·

Non-pharmaceutical interventions $\cdot$ Public health policy $\cdot$ Lockdown $\cdot$ Vaccinations

JEL Classification I10 $\cdot$ I18

\section{Introduction}

Operation Warp Speed has successfully delivered two highly effective COVID-19 vaccines, with additional vaccine candidates undergoing clinical trials. However, vaccine production and distribution are slow, with the Biden administration stated goal of administering only

I am grateful to Dan Bergstresser, Kevin Corinth, Josh Goodman, James Ji, Bob Kaplan, Joel Lander, Blake LeBaron, David Levine, Jean-Paul L'Huillier, Peter Limbach, Bob McDonald, Debarshi Nandy, Andreas Neuhierl, Peter Petri, Steve Cecchetti, Bernd Schlusche; seminar participants at George Mason University, Brandeis University and the American Enterprise Institute; and the anonymous referees for very helpful comments and suggestions.

This article is part of the Topical Collection on Economics of COVID-19

Anna Scherbina

ascherbina@brandeis.edu

1 Brandeis International Business School, Brandeis University, 415 South Street, Waltham, MA 02453, USA 
1.5 million vaccines daily. ${ }^{1}$ In the meantime, the virus continues to claim about as many lives every day as the $9 / 11$ tragedy.

While some European countries have implemented a new round of national lockdowns, there is resistance to imposing more stringent COVID restrictions in the United States. ${ }^{2}$ The costs of a lockdown are felt in real time in the form of inconveniences and lost wages while the benefits from the reduced number of illnesses and deaths come in the future, and as such they may be perceived as hypothetical and underestimated. Moreover, the public may view the pandemic risks as acceptable because children are largely unaffected and frontline workers and first responders are getting protection from the virus by being among the first to be vaccinated (e.g., (Tumpey et al. 2018), Table 12.1).

Despite society as a whole being potentially less concerned about saving the lives of the more vulnerable older adults, ${ }^{3}$ the older people's lives are valuable to them. ${ }^{4}$ The value of life can be quantified by a person's willingness to pay to stay alive, with metrics such as the value of statistical life (VSL) and discounted quality-adjusted life years (dQALY) being widely used in policy decisions. Moreover, the fatality data shows that COVID-19 also poses substantial risks to the lives of younger people who may be unaware of their health vulnerabilities ex-ante and therefore fail to take adequate precautions.

The COVID experience from around the world has shown that centralized policies are critical to achieving an optimal pandemic management. The failed Swedish experiment has illustrated that it may be impossible to selectively protect the vulnerable population without a government intervention. ${ }^{5}$ Analysing U.S. data, (Boehmer et al. 2020) find that increased rates of infection among young people in the June-August 2020 period helped transmit the virus to more vulnerable high-risk groups, such as older adults. This happened in spite of the broad awareness that older population faces higher risks.

Even when a COVID infection is not fatal, it is still costly because the sick consume medical services that could have been allocated to other health conditions. They also miss days of productive work, reducing GDP (or in the case of children and older adults, their caretakers miss productive work days). I perform a cost-benefit analysis of a possible lockdown by comparing its benefits that come from reducing the number of future infections until the vaccination target is reached to the incremental costs a lockdown would impose on the economy and finding the optimal stopping time before incremental costs start to exceed incremental benefits. I model the COVID-19 pandemic curve using the SIR (susceptible, infected, recovered) model widely used in epidemiology. I rely on the COVID literature to obtain the model parameters, such as the basic reproduction number that prevails with the social distancing measures currently in place, as well how it will change during a nation-wide lockdown, similar to lockdowns implemented in Europe in Spring 2020.

\footnotetext{
${ }^{1}$ See, e.g, https://www.nbcnews.com/politics/white-house/biden-ups-vaccine-goal-1-5-million-shots-day-saysn1255597.

2I will use the terms "COVID," "COVID-19" and "SARS-CoV-2" interchangeably.

${ }^{3}$ See, e.g., https://www.texastribune.org/2020/04/21/texas-dan-patrick-economy-coronavirus/.

${ }^{4}$ For example, a Gallup poll showed that older people were more willing than younger people to choose resuscitation or ventilator support when asked about preferences in the event of terminal illness (Gallup and Newport 1991).

${ }^{5}$ https://www.wsj.com/articles/long-a-holdout-from-covid-19-restrictions-sweden-ends-its-pandemic-experiment-11607261658 .
} 
The expected future monetary cost of the COVID pandemic is calculated from the following three components: (1) the loss of productivity due to missed work of the symptomatically ill; (2) the cost of medical interventions that could have been used elsewhere; and (3) the value of lives of the projected fatalities. I estimate that if no additional restrictions are imposed, even with the vaccination program currently in place, the pandemic will cost an additional $\$ 1.3$ trillion going forward if the value of statistical life (VSL) is used to value life and $\$ 368$ billion if life is valued with discounted quality-adjusted life years (dQALY).

Evidence shows that the lockdown measures adopted in parts of the United States and Europe in Spring 2020, which included bans on large social gatherings, closures of public places such as gyms, schools, bars and entertainment venues, and shelter-in-place orders, were highly successful at reducing the virus transmission (e.g., (Courtemanche et al. 2020) and (Flaxman et al. 2020)). The benefit of a lockdown is calculated based on reducing the number of new infections going forward, and therefore avoiding a portion of these costs. Obviously, the longer the lockdown lasts, the larger the reduction in the number of new cases it will achieve. If the policymaker's only objective were to minimize the attack rate (the fraction of the population that will become symptomatically ill), the optimal solution would be to extend the lockdown until the vaccination target is reached. However, each additional week of a lockdown has a lower impact on reducing future infections because the immune population is continuously expanding due to vaccinations, and since the benefits should be balanced against the costs to the economy, a lockdown should be optimally stopped sooner. Analyzing whether it is optimal to start a lockdown a week from now, I find that it is and that such a lockdown should last between two and four weeks, depending on the assumptions made, and will generate a net benefit up to $\$ 653$ billion, or 3\% of GDP.

I additionally consider two hypothetical scenarios. First, I evaluate the effect of the proposal to switch from two to one vaccine doses in order to reach more people sooner. By reducing vaccine effectiveness, this proposal would leave the higher-risk older population more vulnerable to the adverse health consequences of the virus. As a result, the number of deaths will increase. I find that a lockdown would be even more beneficial, generating up to $\$ 302$ billion more in net savings, and its optimal duration will remain the same as under the two-dose vaccination plan. Second, I consider a hypothetical scenario in which the more contagious so-called "U.K. variant" of the SARS-CoV-2 virus becomes the predominant variant in the United States, just like it has in the United Kingdom. If this occurs, the pandemic will be much more devastating, with more people getting sick and dying. I find that a lockdown will bring even greater net benefits, estimated to be up to $\$ 2.2$ trillion, and the optimal lockdown duration will increase by four weeks, to the total of eight weeks, in the main specification. In sum, under all scenarios considered, and with various combinations of plausible assumptions and parameter values, I find that a lockdown is a valuable non-pharmaceutical intervention that will help save a large number of lives and reduce the overall cost of the pandemic.

\section{The Cost-Benefit Analysis}

By limiting physical proximity between people, a lockdown reduces the chance of passing the virus to not-yet-immune persons. A lockdown will reduce the number of new infections 
that occur during the lockdown period and also in the future, once it is lifted, because at the time it is lifted the "seed" of infected individuals spreading the virus will be smaller relative to the no-lockdown baseline.

The longer a lockdown lasts, the more susceptible individuals it will prevent from coming into contact with the infected and "buy" time for the susceptible to get vaccinated. However, each additional week of a lockdown has a declining marginal benefit. Data shows that the number of new cases has already started to decline because a large fraction of the population has become immune to the virus. A lockdown will help speed up this decline in new cases, but the contribution of each subsequent week of a lockdown will get increasingly smaller because the prior lockdown weeks will have already substantially reduced the number of the infected. At the same time, the ongoing vaccination program will contribute to increasing the immune population, thereby allowing the infected fewer opportunities to spread the virus even if the lockdown were lifted. Given the declining marginal benefit, a lockdown should be optimally lifted before its marginal benefit falls below its marginal cost.

In order to quantify the net benefit of a lockdown and determine its optimal duration, I need to estimate the number of infections that a lockdown of a certain duration would help prevent. I start by quantifying the future cost of the pandemic, by projecting how many people are likely to be infected before the pandemic comes to an end due to herd immunity and then assessing the total cost of these projected infections. The costs of an infection are the sum of medical costs, lost productivity, and the value of life for those who die. I employ the SIR model to forecast the number of future infections, using the current initial conditions (the number of currently infected and the fraction of the already recovered and immune), and the so-called "basic reproduction number," $R_{0}$, which is the measure of the virus contagiousness. In the SIR model, an infected individual infects, on average, $R_{0}$ other people at the beginning of the pandemic, when no one in the population has yet acquired immunity. Those recovered from the virus become immune and cannot be reinfected. As the pandemic progresses, the immune fraction increases, and the ability to pass on the virus declines, as a subset of the people with whom an infected individual comes into contact is already immune. The effective reproduction number, $R_{t}$, measures the number of other people an infected person infects on average at time $t$ of the pandemic; hence, $R_{t}$ is lower than $R_{0}$ and declines over time. ${ }^{6}$ The pandemic will end once a sufficient fraction of the population acquires immunity, thereby preventing the further spread of the virus.

A lockdown will help reduce the number of new cases in the next period by reducing the number of people with whom an infected person comes into contact. In terms of the SIR model, the effect of a lockdown will be reflected by a lower $R_{0}$. Once a lockdown is lifted, $R_{0}$ will rise to the pre-lockdown level. However, the projected number of all future infections will lower relative to the no-lockdown scenario because there will be a lower "seed" of infected individuals spreading the virus. The benefit of a lockdown is calculated based on the reduction in total projected cases relative to the no-lockdown benchmark.

In order to perform the cost-benefit analysis, I first use the SIR model to project the number of future symptomatic infections, taking into account the effect of the additional immunity acquired from vaccinations. Next, I estimate the total number of cases that a lockdown of a certain duration can prevent until the pandemic ends and calculate the associated

\footnotetext{
${ }^{6}$ Specifically, $R_{t}=R_{0} \frac{S_{t}}{N}$, where $S_{t}$ is the number of susceptible people in the population and $N$ is the population size.
} 
dollar savings. Finally, I determine the optimal lockdown duration by finding the stopping time at which the incremental benefit falls below the incremental cost.

\section{Estimating the Future Cost of the COVID Pandemic}

In order to estimate the dollar cost of the COVID-19 pandemic in the U.S., I follow the methodology used in studies of the costs of seasonal and hypothetical pandemic influenza outbreaks (e.g., (Molinari et al. 2007) and (CEA 2019)). ${ }^{7}$

\section{Medical Outcomes}

An individual infected with the COVID-19 virus can have two outcomes: they can be asymptomatic or exhibit symptoms. Asymptomatic individuals do not miss work and do not incur any medical costs, although they can still infect others at the same rate as symptomatic individuals. Conditional on being symptomatic, an individual can have one of four progressively worse outcomes: (1) have mild symptoms and require no medical intervention, (2) have more severe symptoms and require an outpatient visit, (3) be hospitalized and survive, and (4) be hospitalized and die. Figure 1 plots the possible outcomes.

An important input into the analysis is the fraction of asymptomatic cases. Mizumoto et al. (2020) analyze the data from the quarantined Diamond Princess cruise ship and find that the asymptomatic fraction was $17.9 \%$. However, given that the Diamond Princess sample consisted predominately of older adults, other studies have since estimated a higher fraction of asymptomatic infections among the general population. For example, BuitragoGarcia et al. (2020) conduct meta-analysis of published papers using data around the world that they assess to be free of the sample selection bias. They report a higher summary estimate of the proportion of the population that become infected with the virus and remain asymptomatic throughout the course of the infection of $31 \%$. CDC's latest version of the "COVID-19 Pandemic Planning Scenarios" 8 also relies on meta-analysis of published papers to come up with an estimate for the asymptomatic fraction. ${ }^{9}$ I use the assumptions from Scenario 5, "Current Best Estimate," that the asymptomatic fraction is 40\%; it is derived as the mid-point of the estimates from published papers. ${ }^{10}$

Table 1 describes the probability that an infected person experiences each of the four possible outcomes of the disease as a function of their age and, when available, health risk status. Given that COVID risks increase with age, I divide the population into age groups (when an estimate for a particular age bin is not available from the literature, I calculate it by weighting the estimates for the overlapping age bins by the corresponding population fraction in each.) I obtain COVID hospitalization risks from Reese et al. (2020) and calculate the estimates for the older age bins using CDC's table on relative hospitalization

\footnotetext{
${ }^{7}$ Throughout the paper, the terms "flu" and "influenza" are used interchangeably.

${ }^{8}$ https://www.cdc.gov/coronavirus/2019-ncov/hcp/planning-scenarios.html\#five-scenarios.

${ }^{9}$ In doing so, CDC acknowledges the limitations of the current studies: "The percent of cases that are asymptomatic, i.e. never experience symptoms, remains uncertain. Longitudinal testing of individuals is required to accurately detect the absence of symptoms for the full period of infectiousness."

${ }^{10}$ This "best estimate" number aligns with estimates from Oran and Topol (2020), a meta-analysis that estimates the asymptomatic fraction to be $40 \%$ to $45 \%$.
} 


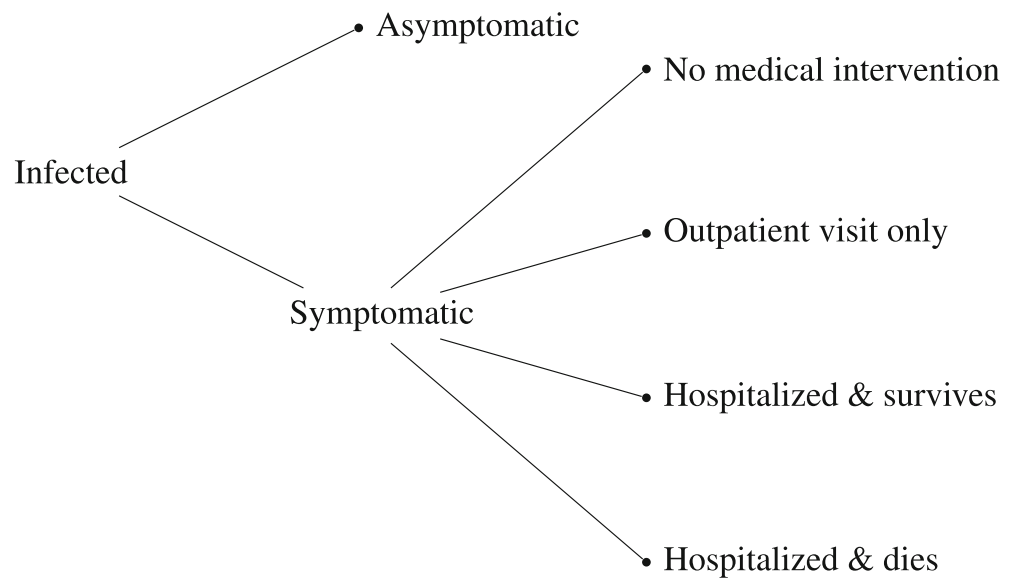

Fig. 1 Outcomes for an infected person. The figure presents possible outcomes for a person infected with the COVID-19 virus

risks by age. ${ }^{11}$ I adjust these estimates for under-reporting by multiplying them by the ratio $2.5 / 7.7=0.32$ ((Reese et al. 2020) find that hospitalized COVID cases are under-reported by a factor of 2.5 and overall COVID cases are under-reported by a factor of 7.7).

Infection fatality rates (probability of dying conditional on being infected with COVID) are obtained from Levin et al. (2020), which is a meta-analysis of the literature and government reports that is restricted to studies of advanced economies, which includes only countries that currently belong in the Organization for Economic Cooperation and Development. In order to fill the more granular age bins in Table 1, I also use the estimates from CDC's COVID-19 Pandemic Planning Scenarios, "Current Best Estimate."

Symptomatic individuals may fall into two groups: high- and low-risk. Patients who fall into high-risk health groups have pre-existing conditions that increase the likelihood of complications. The table provides cost estimates associated with each outcome for a symptomatic individual, as a function of age and health risk. Due to the lack of cost estimates specific to COVID infections and because COVID symptoms and the mode of transmission is similar to those of seasonal influenza, ${ }^{12}$ I use the estimates for the proportion of high-risk individuals as well as medical and productivity costs from the seasonal influenza literature ((Molinari et al. 2007) and (CEA 2019)). However, early evidence indicates that COVID-19 may be more likely than influenza to leave survivors with long-term negative health effects, ${ }^{13}$ which would cause me to underestimate the associated costs of an infection. Finally, for the calculation of the costs of lost productivity due to illness, I follow Barrot et al. (2020) and assume that a missed day of work represents productivity loss of \$520.

For the individuals who die, society loses some productivity due to their inability to work during the period of the illness and, more importantly, the value of life. Policymakers employ several methods to estimate the value of life. Perhaps the most commonly used

\footnotetext{
${ }^{11}$ Available from https://www.cdc.gov/coronavirus/2019-ncov/covid-data/investigations-discovery/hospitalization-death-by-age.html.

${ }^{12}$ See, e.g., the CDC description at https://www.cdc.gov/flu/symptoms/flu-vs-covid19.htm.

${ }^{13}$ See, e.g., https://www.cdc.gov/coronavirus/2019-ncov/hcp/clinical-care/late-sequelae.html.
} 
Table 1 Risks and Costs Associated with a COVID Infection

\begin{tabular}{llllllll}
\hline \multicolumn{1}{l}{ Age Group } \\
\cline { 2 - 7 } \% of US population & $0-19$ & $20-44$ & $45-54$ & $55-64$ & $65-74$ & $75-84$ & $\geq 85$ \\
\hline
\end{tabular}

\section{OUTCOME PROBABILITIES}

Clinical outcomes

Prob. of hospitalization

$$
1.29 \%
$$

$2.27 \%$

$4.23 \%$

$6.17 \%$

$13.96 \%$

$22.34 \%$

$60.00 \%$

Probability of dying (IFR)

$0.003 \%$

Outcomes for symptomatic patients

Proportion high-risk

$$
8 \%
$$

$15 \%$

$24 \%$

$51 \%$

$51 \%$

$51 \%$

Outpatient visit

- low-risk patients

- high-risk patients

$\begin{array}{lllllll}32 \% & 32 \% & 32 \% & 31 \% & 62 \% & 62 \% & 62 \% \\ 77 \% & 63 \% & 63 \% & 63 \% & 82 \% & 82 \% & 82 \%\end{array}$

\section{COST ESTIMATES}

Case not medically attended

Medical cost (all risk)

$\$ 5$

Lost productivity (all risk)

$\$ 260$

$\$ 5$

$\$ 5$

$\$ 260$

$\$ 260$

$\$ 5$

$\$ 260$

$\$ 5$

$\$ 5$

$\$ 5$

Outpatient visit

Low-risk medical cost

\section{$\$ 161$}

$\$ 212$

$\$ 233$

$\$ 254$

$\$ 410$

$\$ 410$

$\$ 410$

Low-risk lost productivity

$\$ 520$

$\$ 520$

$\$ 780$

$\$ 1,040$

$\$ 1,560$

$\$ 1,560$

$\$ 1,560$

High-risk medical cost

$\$ 1,098$

$\$ 1,227$

$\$ 1,234$

$\$ 1,240$

$\$ 806$

$\$ 806$

$\$ 806$

High-risk lost productivity

$\$ 2,080$

$\$ 1,040$

$\$ 1,560$

$\$ 2,080$

$\$ 3,640$

$\$ 3,640 \quad \$ 3,640$

Hospitalization

Low-risk medical cost

Low-risk lost productivity

High-risk medical cost

High-risk lost productivity

$\$ 25,408$

$\$ 32,174$

$\$ 34,960$

$\$ 37,745$

$\$ 19,379$

$\$ 19,379$

$\$ 19,379$

$\$ 4,680$

$\$ 6,240 \quad \$ 6,500$

$\$ 6,760$

$\$ 6,760$

$\$ 6,760$

$\$ 6,760$

$\$ 70,938$

$\$ 80,760 \quad \$ 75,334$

$\$ 69,908$

$\$ 28,346$

$\$ 28,346$

$\$ 28,346$

$\$ 11,960$

$\$ 10,920$

$\$ 11,700$

$\$ 12,480$

$\$ 9,360$

$\$ 9,360$

$\$ 9,360$

Fatalities

\begin{tabular}{llllllll} 
Low-risk lost productivity & $\$ 4,680$ & $\$ 6,240$ & $\$ 6,500$ & $\$ 6,760$ & $\$ 6,760$ & $\$ 6,760$ & $\$ 6,760$ \\
High-risk lost productivity & $\$ 11,960$ & $\$ 10,920$ & $\$ 11,700$ & $\$ 12,480$ & $\$ 9,360$ & $\$ 9,360$ & $\$ 9,360$ \\
Value of statistical life $(\$$, mil.) & 5.76 & 12.34 & 10.05 & 7.75 & 5.29 & 5.29 & 5.29 \\
\hline
\end{tabular}

SOURCES For hospitalization risks: (Reese et al. 2020) and CDC; for IFR: (Levin et al. 2020) and CDC's "COVID-19 Pandemic Planning Scenarios," Scenario 5; for high- and low-risk probabilities and cost estimates: (Molinari et al. 2007) and (CEA 2019); for productivity losses: (Molinari et al. 2007) and (Barrot et al. 2020); for VSL: (Aldy and Viscusi 2008) and (CEA 2019); author's calculations

NOTES This table presents the risks and per-person medical risks and productivity costs associated with various outcomes of the COVID-19 infection

is the value of statistical life (VSL), which is estimated from studies assessing how much money people are willing to pay to increase the probability of staying alive. Following (CEA 2019), I use inflation-adjusted VSL values by age group obtained from Aldy and Viscusi 
(2008), who estimate them from the wage premia paid by riskier jobs. ${ }^{14}$ Because the value of medical costs are already factored into the value of life estimates, I do not add the medical costs for people who die. To calculate future costs of each pandemic management scenario considered, I calculate the total number of symptomatic individuals in each risk and age group that would fall into each of the four possible disease outcome categories and then multiply them by the associated costs, finally summing them up to obtain the total cost.

\section{The Evolution of the Pandemic Curve}

I use the SIR model to project the number of new COVID-19 infections at a weekly frequency. The starting point is 02/03/2021 (this is week 0), and I use the initial conditions as of this date to project the further evolution of the pandemic in the United States. I calculate the forward-looking costs from this time on and ignore the costs already incurred. Given the requirement for sick people to self-isolate for 14 days, I assume that a newly infected person is contagious for two weeks, during which time they will infect $R_{0}$ other people at the beginning of the pandemic, when no one in the population has immunity. The number of other people that a contagious person infects is assumed to be spread evenly across the two weeks. Per SIR model, I assume that a recovered individual develops immunity and will not get infected or infect others, and those currently ill cannot be re-infected.

To estimate the fraction of the population already recovered from COVID, it is important to account for under-reporting of COVID cases in the official statistics. I use the latest estimate of under-reporting from CDC, Reese et al. (2020), which analyzes four reasons for under-reporting - asymptomatic cases, symptomatic individuals not seeking medical attention, people seeking medical attention but not getting tested for COVID, and false negative test results-and estimates that due to these reasons, only one in 7.7 COVID cases ends up being detected and reported. ${ }^{15}$

In addition to the population immunity acquired via the recovered individuals, I account for the additional contribution to population immunity from the ongoing vaccination program, with the stated goal to vaccinate $70 \%$ of the population. ${ }^{16}$ Two vaccines are currently approved in the United States, Pfizer-BioNTech and Moderna, both of which requires two doses administered with a gap of three and four weeks, respectively. The two vaccines have similar effectiveness, and I will use the data for Pfizer-BioNTech in modeling the incremental effect of the vaccination program. Polack et al. (2020) establish that some protection is achieved already after the first Pfizer-BioNTech vaccine dose: The vaccine has an efficacy of 52\% after the first dose, and of $95 \%$ after the second dose. In modeling the effect of the vaccine, I assume that the first vaccine dose renders the vaccinated person immune and unable to pass the virus to others with a probability of $52 \%$ and the second dose, with the probability of $95 \%$.

Consistent with CDC's recommendation, I model that that vaccination starts with the most at-risk older population groups and progresses to the less vulnerable younger groups. ${ }^{17}$

\footnotetext{
${ }^{14}$ While the authors are unable to estimate VSL for children, other studies obtain estimates from parents' willingness to pay for children's medical costs. The children's VSL estimate does not enter into the total cost calculation since COVID-19 studies assess a near-zero fatality risk for the younger age group.

${ }^{15}$ As of February 3, 2021, CDC reports that there were 26.3 million COVID cases in the United States up to that date, and after adjusting for under-reporting, this number implies that more than half of the population was previously infected with COVID.

${ }^{16}$ https://www.commonwealthfund.org/publications/issue-briefs/2020/dec/how-prepared-are-states-vaccinatepublic-covid-19.

${ }^{17}$ https://www.cdc.gov/mmwr/volumes/69/wr/mm6949e1.htm.
} 
CDC reports that as of $2 / 3 / 2021$ a total of $33,878,254$ vaccine doses were administered. Going forward, I presume that the Biden administration goal of administering 1.5 million vaccine doses daily will be implemented ${ }^{18}$ and, with vaccinations continuing seven days a week, 10.5 million vaccine doses will be administered weekly. I further assume that the vaccination program will be completed when $70 \%$ of the U.S. population is fully vaccinated, which will happen around mid-November 2021. Finally, due to the overwhelming under-reporting of COVID cases, I assume that the vaccination program will not distinguish between the individuals who have not yet had COVID and those already recovered and immune, hence, a portion of the vaccines will be "wasted" on the already immune individuals. After forecasting the total number of new cases in every week with the SIR model, I "distribute" these cases across the age bins based on the age bins' relative proportions of susceptible individuals (i.e., those not yet vaccinated or having already had the disease) in that week.

A critical input into the SIR model is the basic reproduction number, $R_{0}$. CDC's "current best estimate" for the no-intervention COVID $R_{0}$ for the U.S. is $2.5 .{ }^{19}$ However, increased sanitation, social distancing and the widespread use of face masks widely implemented in the United States were successful in reducing the virus reproduction number below this value. For example, Morley et al. (2020) study the effect of reduced personal mobility resulting form social distancing restrictions on the COVID reproduction number in several New York State counties. They use data from Unacast, a company that tracks and assigns letter grades to the reductions in mobility across various geographic areas; larger reductions in mobility are assigned higher grades. The figure presented on page 610 of the paper reports the effective reproduction rate that corresponds to each Unacast's mobility-reduction grade (I will use Panel B of the figure that removes outliers from the data).

U.S.-wide mobility reduction roughly corresponds to Unacast's grade " $D$ " assigned for a 40\%-74\% reduction in mobility. For example, Pishue (2020) finds that between March 14 and April 17 personal vehicle-miles traveled in the United States dropped by 46\%, on average. Using a mobility index that aggregates cell phone data to capture changes in human movement over time, Archer et al. (2020) document a fluctuating but slightly larger drop in mobility, which is over 50\% on average. Finally, Google's COVID-19 Community Mobility Report for the United States reports a similar-magnitude decline in the number of visits to public spaces. According to Morley et al. (2020), the "D" grade corresponds to a reproduction number of roughly 1.75 .

Since the estimates in that paper were made during the early stages of the pandemic, when population-wide immunity was still low, I will use this number as my assumption for the basic reproduction number, $R_{0}$, that prevails with the interventions currently already in place. This $R_{0}$ estimate matches the currently observed data very well. Specifically, after inputting the number of recovered and therefore immune individuals into my SIR model with this $R_{0}$ parameter, I can match the number of people infected with COVID in the previous week and the current effective reproduction number, $R_{t} \cdot{ }^{20}$

Figure 2 depicts a weekly-frequency projection of the number of new symptomatic COVID cases. It shows that with the current immune fraction of the population and the ongoing vaccination program, the number of new cases is projected to decline. Absent a

\footnotetext{
${ }^{18}$ https://www.cnn.com/2021/01/25/politics/biden-vaccine-distribution/index.html.

${ }^{19}$ https://www.cdc.gov/coronavirus/2019-ncov/hcp/planning-scenarios.html\#five-scenarios.

${ }^{20}$ I estimate the nation-wide $R_{t}$ as the state-population-weighted average of $R_{t}$ estimates by state reported on the website rt.live on $02 / 03 / 2021$; it is estimated to be 0.87 , which implies that the number of new cases nation-wide is already declining.
} 


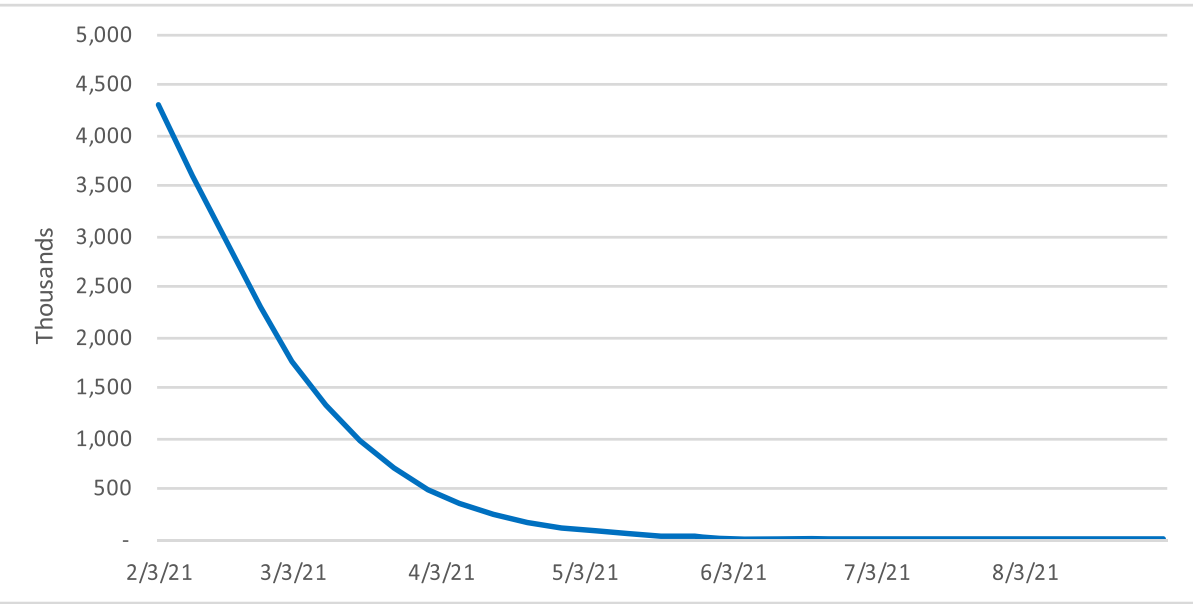

Fig. 2 New symptomatic cases with no lockdown. SOURCES CDC COVID Data Tracker, Census Bureau, author's calculations. SIR model inputs described in Table 5 of the Appendix. The figure plots the predicted number of new symptomatic cases produced by the SIR model. The model includes the effect of additional immunity acquired through vaccinations

lockdown, the pandemic is going to be largely over by September 2021, and it will bring about 17.5 million additional symptomatic illnesses and 203,337 more deaths. ${ }^{21}$ When the costs of symptomatic illnesses and the value of life are taken into account, these projections translate into a cost of $\$ 1.3$ trillion going forward, with medical costs and lost productivity contributing about $6 \%$ to this value and the rest attributed to the value-of-life losses.

\section{Modeling the Effect of a Lockdown at Different Durations}

By drastically reducing mobility, a lockdown holds the promise to significantly lower the virus reproduction number relative to the current value. It has been estimated that the Winter 2020 Wuhan lockdown reduced the COVID effective reproduction rate from above two to $0.3{ }^{22}$ Given that lockdowns are likely to be less restrictive and more leniently enforced in Western countries, the drop in $R_{0}$ is likely to be more modest. Studies that analyze the effect of the Spring 2020 lockdowns in the United States and in Europe using mobility data, such as Google Community Mobility Index and smartphone GPS location data, find that lockdowns led to significant reductions in spatial movements (e.g., (Pepe et al. 2020)). Lockdowns in Western countries were also found to generate large reductions in the virus reproduction rate. Using hospitalization records, Salje et al. (2020) estimate that in France the lockdown reduced the reproduction number by $77 \%$, from 2.90 to 0.67 . Flaxman et al. (2020) perform a broader analysis of the effect on the Spring 2020 lockdown across 11 European countries using data on COVID-related deaths and find that lockdowns on average decreased the virus reproduction rate by $81 \%$ to an average value of 0.66 across these countries. Using a survey, Jarvis et al. (2020) assess that in the U.K. the Spring 2020 lockdown lead to a $76 \%$ reduction in the number of contacts, which they estimate to reduce the

\footnotetext{
${ }^{21}$ The projected fatality rate is lower than the assumed average IFR because of the effect of the vaccination program that prioritizes the more vulnerable older population.

${ }^{22}$ https://qz.com/1834700/rt-the-real-time-r0-guiding-how-to-lift-coronavirus-lockdowns/.
} 


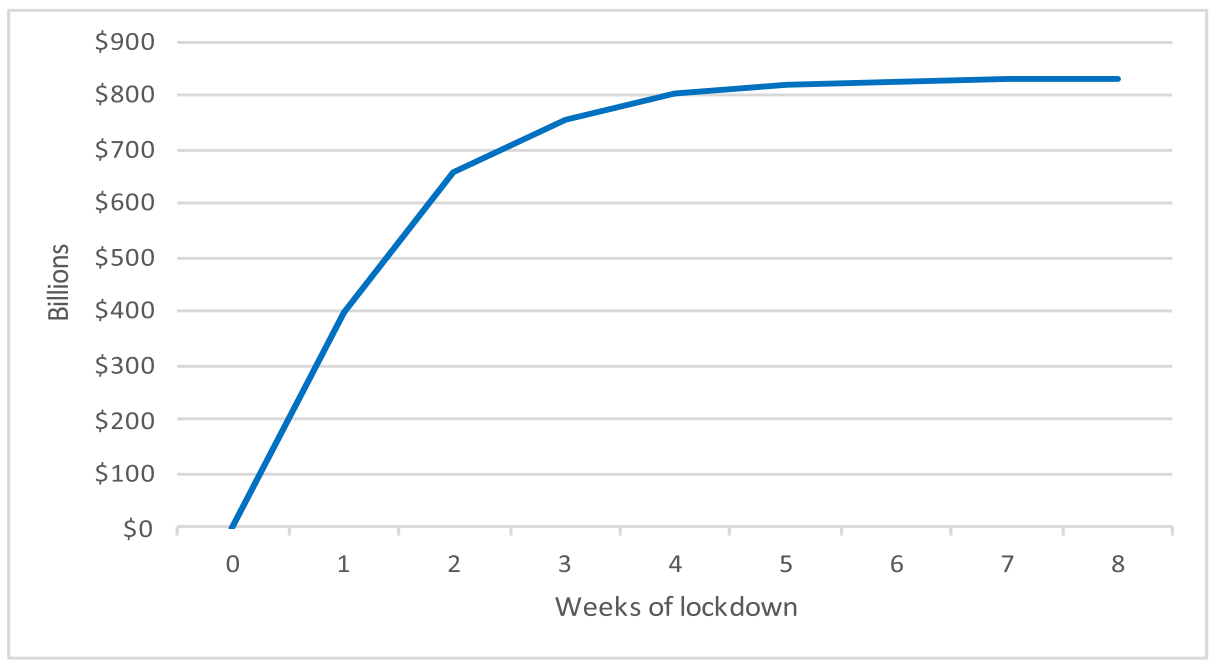

Fig. 3 Savings from a lockdown as a function of its duration. SOURCES CDC COVID Data Tracker, Census Bureau, author's calculations. SIR model inputs and other inputs used in the calculations are described in Table 5 of the Appendix. The figure plots projected savings from a lockdown as a function of the number of weeks it is kept in place, assuming that it is imposed a week from now

$R_{0}$ from 2.6 prior to lockdown to a value of 0.62 . Given the previously discussed estimate of the no-intervention $R_{0}=2.5$ for the United States, the average of these percent reductions implies that a lockdown will produce $R_{0}=0.58$. However, to err on the conservative side and because the U.K. is most culturally similar to the United States, I will use the U.K. estimate and assume that a national lockdown in the U.S. will achieve $R_{0}=0.62$. In the sensitivity analyses, I use an even more conservative assumption that the basic reproduction number achievable with a lockdown is $25 \%$ higher, or 0.775 .

I assume that if a lockdown were to be imposed, it would start a week from now, at the beginning of week 1. After a lockdown is lifted, the basic reproduction number will revert to the pre-lockdown value of 1.75. Figure 3 plots the incremental savings achieved from a lockdown as a function of the number of weeks that it is kept in place relative to the baseline of no lockdown. The figure shows that the savings increase with each additional week of a lockdown albeit at a declining rate: the rapid reduction in the number of infected individuals through a lockdown becomes less valuable since the prior lockdown weeks have already substantially reduced the number of infected people spreading the virus, and vaccinations are increasing the immune fraction in the meantime.

\section{Incremental Cost of a Lockdown}

When assessing the incremental impact of a lockdown on the economy, it is important to note that even in the absence of lockdown orders, a global pandemic depresses economic activity relative to normal times due to voluntary social distancing. Chen et al. (2020) collect a number of high-frequency indicators of economic activity in the United States and Europe, such as electricity usage and mobility indicators, as well as additional economic indicators for the United States, such as unemployment insurance claims and employeehours worked for small and medium sized businesses that employ hourly workers. The paper 
documents large reductions in mobility and economic activity even before the adoption of stay-at-home orders and nonessential business closures, and more so in places with more severe COVID outbreaks, indicating that people voluntarily limited their activities in order to protect themselves and others from the virus.

Similarly, IMF (2020) uses high-frequency mobility indicators and shows that mobility decreases not only as a result of lockdown orders but also in response to rising COVID cases. The paper estimates that lockdown orders contributed about $40 \%$ and voluntary social distancing about $60 \%$ to the total decrease in mobility during lockdowns in advanced economies (Figure 2.2 of IMF (2020)).

I combine several estimates for the incremental cost that a lockdown would impose on the U.S. economy. Using a set of assumptions for which economic sectors would be affected and by how much, OECD (2020) estimates that for the G7 economies national lockdowns would cause annual GDP growth to decline by up to 2 percentage points per month of a lockdown. This translates into a GDP decline of $\$ 107$ billion per week for the United States $(0.5 \% \times$ $\$ 21.43$ trillion). However, this estimate is not incremental to the natural decline of economic activity caused by the pandemic. If, as discussed above, voluntary social distancing during the pandemic contributes about $60 \%$ to the reduction in economic activity, in line with the results discussed above, the incremental economic cost of an imposed lockdown will be about $40 \%$ of that estimate, or about $\$ 43$ billion per week.

Scherbina (2020) analyzes which sectors of the economy will be incrementally affected by a lockdown and by how much and also accounts for the additional costs of productivity losses caused by homeschooling demands on working parents. She estimates the incremental cost of a lockdown to be $\$ 35.79$ billion per week.

Barrot et al. (2020) obtain a slightly lower estimate for the lockdown cost, $\$ 32$ billion per week. Specifically, they estimate the number of workers in each U.S. state employed in the sectors that were closed in that state's Spring 2020 lockdown and who are unable to work from home (the total for the country is estimated to be 12.6 million workers) and multiply this number by the share of U.S. GDP per worker per week $(\$ 2,600)$ to arrive at the final estimate.

These three estimates are relatively close, and I will use the average of these estimates of $\$ 36.93$ billion per week, when assessing the optimal lockdown duration. It must be noted that a number of non-economic costs and benefits of a lockdown have not been considered in the calculation above, as discussion in the Sensitivity Analyses subsection. Therefore, I also consider a more conservative assumption for the incremental cost of a lockdown, assuming that it is $25 \%$ higher than the estimate above.

\section{Optimal Lockdown Duration}

Optimally, the lockdown should end before its incremental benefit falls below its incremental cost to the economy. Figure 4 plots the incremental benefit of each additional week of a lockdown against its incremental cost to the economy. The incremental benefit line is the first difference of the savings line depicted in Fig. 3. (Because savings initially grow fast and then start to level off, the incremental benefit line declines, first quickly and then slowly.) The incremental savings line crosses the incremental cost line after four weeks. Therefore, four weeks is the optimal lockdown duration. After subtracting the incremental cost of the lockdown incurred over this time $(4 \times \$ 36.93$ bil.) from the incremental savings realized from preventing a subset of future infections, I estimate the associated net benefit relative to the baseline scenario of no lockdown to be $\$ 653$ billion, which is about 3\% of GDP. 


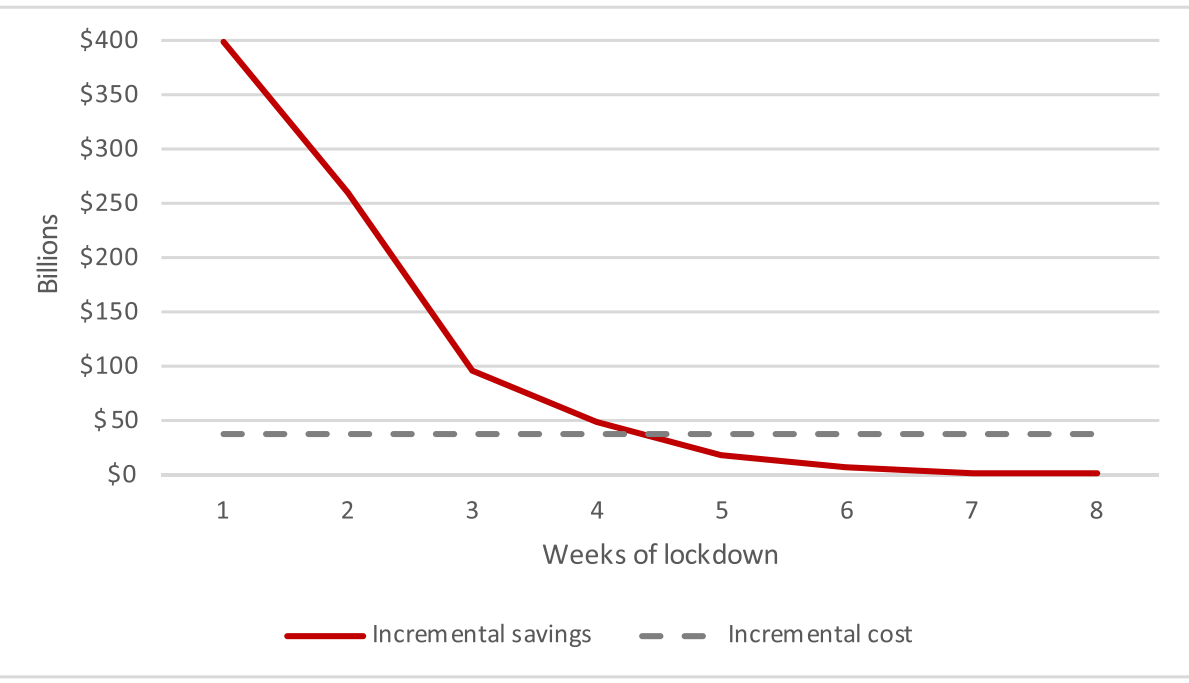

Fig. 4 Incremental costs and savings of each additional week of a lockdown. SOURCES CDC COVID Data Tracker, Census Bureau, author's calculations. Specific sources for SIR model inputs and incremental savings and cost estimates of a lockdown are provided in Table 5 of the Appendix. Assuming that a lockdown is imposed a week from now, this figure plots projected incremental costs and savings of extending lockdown by another week, to the number of weeks specified on the horizontal axis

\section{Sensitivity Analyses}

Given the uncertainty associated with some of my model inputs, I consider some alternative assumptions. Specifically, I consider changing the methodology for valuing life that would assign an even lower value to the lives of the elderly who are at a higher risk of COVID deaths, a lower assumption for lockdown effectiveness, a higher incremental cost, and a lower IFR.

\section{Valuing Life with Discounted Quality-Adjusted Life Years}

So far, I have used VSL to value life. However, health-adjusted life years (HALY) has been gaining popularity in recent years. Here I consider the quality-adjusted life years (QALY) methodology, which is perhaps the most widely used type of HALY (e.g., Neumann and Greenberg 2009, Gold et al. 2002, Hubbell 2006 and Prieto and Sacristán 2003). The morbidity or quality-of-life component is captured by a quality-of-life weight (QOL), which takes values between 0 and 1 , with 0 representing death and 1 perfect health. The number of quality-adjusted life years (QALY) lived in one year is equal to the individual's QOL in that year.

I follow Sassi (2006) to calculate the discounted value of all future quality-adjusted life years (dQALY):

$$
\mathrm{dQALY}=\sum_{t=a}^{a+L} \frac{Q O L_{t}}{(1+r)^{t-a}},
$$

where a is the current age, $L$ is the residual life expectancy at age $a, Q O L_{t}$ is the expected health-related quality of life in year $t$, and $r$ is the discount rate. I use a discount rate of $3 \%$ as is common in the literature (e.g., Sassi 2006 and Hubbell 2006). The life expectancy for 
Table 2 Value of Discounted Quality-Adjusted Life Years, by Age

\begin{tabular}{llllllll}
\hline & \multicolumn{1}{l}{ Age Group } \\
\cline { 2 - 9 } & $0-19$ & $20-44$ & $45-54$ & $55-64$ & $65-74$ & $75-84$ & $\geq 85$ \\
\hline Value of dQALY ((\$, mil.) & 4.05 & 3.44 & 2.73 & 2.22 & 1.71 & 1.14 & 0.82 \\
\hline
\end{tabular}

SOURCES (Nyman et al. 2007) for QOL weights; National Vital Statistics Reports for life expectancy by age; author's calculations

NOTES This table presents the dollar value of discounted quality-adjusted life years, calculated at the lower boundary of each age group. The discount rate is $3 \%$ per year, and the dollar value of QALY is $\$ 150,000$

the U.S. population is obtained from Table VI of the 2020 National Vital Statistics Reports. I use cross-sectional average QOL weights by age estimated by Nyman et al. (2007) for the U.S. population using response data for the Medical Expenditure Panel Survey (Table 1 of the paper).

To translate the value of life into monetary terms when evaluating cost-effectiveness of medical interventions, the Institute for Clinical and Economic Review uses a range of $\$ 50,000-\$ 150,000$ per QALY. Song and Lee (2018) conduct a survey of the general Korean population and find that the willingness to pay for a cure treatment is more than twice as high as for a non-cure treatment. Since my objective is to value the lives of potential COVID fatalities, I will use the highest value of this range, that is $\$ 150,000$ per QALY. The estimates of QALY-based monetary values of life are provided in Table 2, estimated for the lowest bound of each age range.

Despite their increasing popularity, quality-adjusted life-year valuations (and HALY's more generally) have been criticized on technical and ethical grounds. By comparing dQALY values in Table 2 to VSL values in Table 1, it can be seen that the former assign increasingly lower values to older age groups. The reason is that older people have fewer years of life remaining, and these years are of a worse quality due to deteriorating health. Likewise, dQALY would assign a lower value of life to people with disabilities and chronic health conditions relative to healthy people of the same age because the lower embedded QOL values. ${ }^{23}$ On the technical side, a utility function has to have a very specific and, perhaps, unrealistic functional form, with features such as independence between life years and health status, in order to be consistent with the QALY maximization (e.g., Pliskin et al. 1980 and Prieto and Sacristán 2003).

When the dQALY methodology is used to value life, absent a lockdown, the pandemic is projected to cost $\$ 368$ billion going forward, with lost productivity and medical expenses representing $22 \%$ of this total and the value-of-life losses making up the rest. Table 3 presents the estimates of the optimal lockdown duration and the associated net savings by using dQALY instead of VSL to value life. It shows that a lockdown is still optimal under all assumptions considered, but its length is reduced by one week compared to when VSL is used. The net savings, computed as the incremental benefit achieved from reducing the number of future infections and deaths minus the incremental cost of the lockdown, are now estimated to be substantially lower because of the lower value that this method assigns to the lives of the older individuals who are over-represented among the COVID victims.

\footnotetext{
${ }^{23}$ See, e.g., Gold et al. (2002) for a discussion of the ethical challenges associated with using health-adjusted life expectancy to estimate the value of life.
} 
Table 3 Sensitivity of the optimal lockdown duration to alternative assumptions

Assumptions

\begin{tabular}{|c|c|c|c|c|}
\hline Lockdown $R_{0}$ & $\begin{array}{l}\text { Life is valued } \\
\text { with }\end{array}$ & $\begin{array}{l}\text { Incremental cost } \\
\text { of lockdown }\end{array}$ & $\begin{array}{l}\text { Optimal } \\
\text { lockdown } \\
\text { duration }\end{array}$ & $\begin{array}{l}\text { Net savings relative to } \\
\text { no-lockdown baseline } \\
\text { (\$, billion) }\end{array}$ \\
\hline \multirow[t]{4}{*}{0.620} & \multirow[t]{2}{*}{ VSL } & $\$ 36.93$ bil. & 4 weeks & $\$ 653.13$ \\
\hline & & $\$ 46.16$ bil. & 4 weeks & $\$ 616.20$ \\
\hline & \multirow[t]{2}{*}{ dQALY } & $\$ 36.93$ bil. & 2 weeks & $\$ 114.26$ \\
\hline & & $\$ 46.16$ bil. & 2 weeks & $\$ 95.79$ \\
\hline \multirow[t]{4}{*}{0.775} & \multirow[t]{2}{*}{ VSL } & $\$ 36.93$ bil. & 4 weeks & $\$ 578.29$ \\
\hline & & $\$ 46.16$ bil. & 4 weeks & $\$ 541.36$ \\
\hline & \multirow[t]{2}{*}{ dQALY } & $\$ 36.93$ bil. & 2 weeks & $\$ 89.00$ \\
\hline & & $\$ 46.16$ bil. & 2 weeks & $\$ 70.53$ \\
\hline
\end{tabular}

SOURCES Author's calculations

NOTES This table presents the optimal lockdown duration as a function of the assumptions listed in the table. The right-hand column presents the incremental net savings of a lockdown of optimal length calculated as its benefits minus the associated costs incurred over the lockdown duration

\section{Other Incremental Impacts of a Lockdown}

New literature has emerged that studies the non-economic effects of the Spring 2020 lockdowns. However, at this time, it may be too speculative to assign a dollar value to these additional effects that the literature finds since they are still imprecisely estimated.

Mental Health There is evidence that symptoms of depression and anxiety have increased during the lockdown. Pieh et al. (2020) evaluate several mental health and well-being indicators through an online survey with 1,006 respondents in the United Kingdom during the COVID-19 lockdown and find that the prevalence of depressive and anxiety symptoms increased relative to the pre-pandemic period. However, it is unclear from the study how much of this effect can be attributed to the pandemic itself and whether an incremental impact of a lockdown is positive or negative. Furthermore, in what could be interpreted as another negative indicator for mental health, the American Medical Association reports that the number of opioid and other drug-related deaths has increased during the COVID pandemic. ${ }^{24}$ However, more research needs to be done to identify how much of the overdose increase can be attributed to the Spring lockdown.

Despite the evidence that lockdowns may have adverse effects on mental health, data does not show a positive association between lockdowns and suicides. Faust et al. (2020) study records from the Massachusetts Department of Health Registry of Vital Records and Statistics from January 2015 through May 2020 and find that suicide rates have actually decreased to 0.67 per 100,000 person-months from 0.81 per 100,000 person-months during the same period of 2019. Similarly, German data shows that suicides declined during the Spring 2020 lockdown relative to the same period of 2019, which may be partly explained

\footnotetext{
${ }^{24}$ https://www.ama-assn.org/system/files/2020-11/issue-brief-increases-in-opioid-related-overdose.pdf.
} 
by the lockdown's positive incremental effect on mental health, for example by reducing anxiety about being infected, eliminating commute to work, and allowing more time with family. ${ }^{25}$ More research is needed to help precisely isolate the incremental effect of lockdowns on mental health.

Traffic Injuries and Fatalities A clear benefit of a lockdown is a reduction in traffic and the ensuing decline in the number of traffic injuries and fatalities, which were estimated to fall by half in California during the Spring 2020 lockdown (Shilling and Waetjen 2020). For the country as a whole, the National Highway Traffic Safety Administration estimates that for the April-June 2020 period, 302 fewer traffic deaths were recorded relative to the same period in 2019. ${ }^{26}$ This reduction in traffic deaths translates into a VSL benefit of $\$ 202$ million for each week of the lockdown (using the population-average VSL of $\$ 8.68$ million), and the benefit is even higher if the medical costs of caring for the injured are taken into account.

Environmental Impact Another benefit of reduced traffic is less pollution, which has health benefits. Venter et al. (2020) utilize a network of air quality stations distributed across 34 countries to measure the air quality during the lockdown period up until May 15, 2020. They estimate that the air quality has substantially improved, which resulted in large public health benefits. The study estimates that a total of 49,900 pollutant-related deaths and 89,000 pediatric asthma emergency room visits were avoided in the 34 countries in the study sample. Similarly, Archer et al. (2020) document that the reduction in personal mobility caused by the COVID pandemic lead to a significant decrease in $\mathrm{NO}_{2}$ concentrations in the United States.

Crime Spring lockdowns are documented to have reduced the overall crime rate but increased the incidence of domestic violence. Citing the "opportunity theory" of crime, which posits that restrictions on mobility and social interactions will present fewer opportunities for criminal activity, the United Nations Office on Drugs and Crime (UNODC 2020) investigates crime rates around the world and documents that reported incidents of robbery, theft and burglary declined by more than 50 per cent in most countries, and the declines were larger in countries with stricter lockdown regimes (however, the report notes that some of the decline may be attributed to under-reporting). The number of homicides has also greatly declined, but only in some countries, and started rebounding once lockdown measures were relaxed.

These findings are largely corroborated in Bullinger et al. (2020), who analyze crime data and 911 calls made in Chicago during the Spring 2020 stay-at-home orders. They find that overall crime-related arrests decreased by $57 \%$ and 911 calls decreased by $6 \%$ during this period. However, 911 calls reporting domestic violence have increased by $7 \%$, though domestic-violence-related arrests decreased by $27 \%$. The authors speculate that the decrease in domestic violence arrests may be partly explained by under-reporting. The increase in the number of 911 calls reporting domestic violence during the pandemic is consistent with evidence presented in other papers (e.g., (Leslie and Wilson 2020)).

Reduction in Overall Mortality Kung et al. (2020) show that the New Zealand lockdown lead to an $11 \%$ decrease in the weekly death rate relative to historical trends. The authors

\footnotetext{
${ }^{25} \mathrm{https} / / / \mathrm{www} . d w . c o m / \mathrm{en} / \mathrm{is}$-social-distancing-during-coronavirus-causing-more-suicides/a-53584282.

${ }^{26} \mathrm{https} / /$ www.reuters.com/article/us-health-coronavirus-usa-traffic-exclus/u-s-traffic-deaths-fell-after-coronavirus-lockdown-but-drivers-got-riskier-idUSKBN26M6KR.

${ }^{27}$ This decrease may be partly explained by a new policy to limit or halt prosecutions of low-level, non-violent offenses, adopted by the Chicago Police Department on March 20 in an effort to protect first responders.
} 
provide evidence that this reduction was largely explained by the reduction in seasonal influenza and pneumonia, though other factors, such as fewer traffic deaths, reduced air pollution and lower occupational hazards, likely played a role as well.

Additional Incremental Effects A lockdown would likely have additional shorter- and longer-term costs and benefits. One clear benefit is that an increased reliance on technology will help boost future GDP growth. An increased ability to work remotely will allow more individuals to enter the workforce, and companies will be able achieve a higher return on investment by saving on real estate leases and travel costs. Moreover, with less commuting and reduced traffic, employees may gain productive hours.

Lockdowns also have a number of negative incremental effects, in addition to the ones already mentioned. Reduced access to medical services may lead to negative health consequences in the longer term. A lower education quality may result in a marginally less productive future workforce. Lockdowns may cause an incremental increase in the number of bankruptcies, resulting in dead-weight losses associated with a less efficient re-deployment of business assets. In the sensitivity analyses presented in Table 3, I make a more conservative assumption for the incremental cost of a lockdown by increasing it by $25 \%$, to $\$ 46.16$ billion a week. The table shows that for the main results, the higher incremental cost does not shorten the optimal lockdown duration but reduces the estimated net savings.

\section{Lower IFR Assumption}

The IFR estimates in the paper are based on meta-analyses of academic papers and government data for developed economies. The implied population-weighted average IFR of $1.33 \%$ is consistent with a number of other estimates for the COVID mortality rate. However, I also try a more conservative estimate, by assuming that the IFR for each age bin is reduced by $25 \%$, thus resulting in a population-weighted average IFR of $1.00 \%$. Under this assumption, absent a lockdown, the future death toll is projected to be 153 thousand, and the future cost of the pandemic to be $\$ 997$ billion, with medical costs and lost productivity representing $8 \%$ of this number and the rest attributed to value-of-life losses. When dQALY are used to value life, the pandemic is projected to cost $\$ 294$ billion going forward, with medical and productivity costs representing $27 \%$ of this number.

Table 6 in the Appendix reports the estimates of the optimal lockdown duration and the corresponding net savings for this IFR assumption. Compared to the main results, the optimal lockdown duration is shortened by one week in four of the eight specifications considered; and since projected fatalities are lower, the estimated net benefits of a lockdown are reduced.

\section{Alternative Scenarios}

Here I will consider the optimal lockdown policy under two hypothetical scenarios: one scenario under which the vaccination program will administer only one vaccine dose instead of two and one scenario under which the so-called "U.K. variant" of SARS-CoV-2 becomes the predominant variant in the U.S.

\section{Switching to a Single Vaccine Dose}

Given the slow speed of vaccinations, it has been proposed to administer only one rather than two doses of the approved vaccines in order to vaccinate more people in a shorter time 
span. ${ }^{28}$ I incorporate this proposal into the model by assuming the same speed of vaccination and the same vaccination priorities as before, but administering a single vaccine dose to all. As described above, the efficacy of a single vaccine dose is only $52 \%$. With this proposal in place, the vaccination target will be reached by mid-June 2021 , when $70 \%$ of the population gets a single vaccine dose.

Compared to the current vaccination plan, switching to the one-dose plan will result in worse outcome because the more at-risk older population groups will get a worse protection from the virus: going forward, this vaccination plan will result in 91,151 additional deaths compared to the two-dose baseline, the total cost of the pandemic will increase by $\$ 481.34$ billion relative to the baseline when VSL is used to value life and $\$ 92.92$ billion when dQALY is used.

A lockdown will be even more helpful in reducing the costs of the pandemic, and the optimal lockdown duration will remain the same as under the current vaccination program for all eight sets of assumptions considered. However, the net savings of a lockdown will increase by up to $\$ 302$ billion. The results are reported in the Appendix Table 7 .

\section{The U.K. Variant}

Presently, particularly concerning is the so-called "U.K. variant," a mutation of the SARSCoV-2 virus that was first identified in the United Kingdom in September 2020 and since then has become the predominant variant circulating in the country. ${ }^{29}$ Citing several studies, ECDC (2021) reports that, compared with the variant that was first detected in Wuhan, China, and then spread around the globe (the Wuhan variant hereafter), the U.K. variant is substantially more transmissible, and its $R_{0}$ is higher than that of the Wuhan variant by between $36 \%$ and $75 \%$. The report claims that the U.K. variant is comparable to the Wuhan variant in the infection severity and that there is evidence of cross-immunity between variants, though the latter claim needs to be investigated further. According to the report, the U.K. variant has spread to at least 60 other countries, and CDC notes that it was first detected in the U.S. at the end of December $2020 .{ }^{30}$

I model the optimal lockdown policy under a hypothetical scenario that, starting in week 1, the U.K. variant of SARS-CoV-2 becomes the predominant variant in the U.S., just like it has in the U.K. I assume that $R_{0}$ of the U.K. variant exceeds $R_{0}$ of the Wuhan variant by $56 \%$ (the midpoint of the estimates discussed above), making its $R_{0}$ equal to $2.5 \times 1.56=3.888$. Assuming that mitigation measures currently in place achieve the same 30-percent reduction in the virus $R_{0}$, they would reduce $R_{0}$ of the U.K. strain to 2.721 .

Absent a lockdown, with the current vaccination schedule in place and assuming that the vaccines do not lose effectiveness against the U.K. variant, ${ }^{31}$ the pandemic will result in 498,278 deaths going forward, and its forward-looking cost will be $\$ 3.1$ trillion when VSL is used to value life and $\$ 900$ billion when dQALY is used. Assuming that a lockdown is able to reduce $R_{0}$ of the U.K. variant by $76 \%$ as it has for the Wuhan variant, $R_{0}$ will drop to 0.933 . I also consider a more conservative assumption that a lockdown $R_{0}$ is $25 \%$ higher and equals 1.166 .

\footnotetext{
${ }^{28}$ See, e.g., https://www.marketwatch.com/story/slaoui-proposes-a-single-dose-of-modernas-covid-19-vaccineto-speed-vaccinations-11609788479.

${ }^{29}$ See, e.g., https://www.cdc.gov/mmwr/volumes/70/wr/mm7003e2.htm?s_cid=mm7003e2_w.

${ }^{30}$ https://www.cdc.gov/coronavirus/2019-ncov/transmission/variant.html.

${ }^{31}$ See, e.g., https://www.sciencefocus.com/news/pfizer-vaccine-appears-to-be-effective-against-uk-coronavirusvariant/.
} 
Table 4 Optimal lockdown duration for the U.K. variant

Assumptions

\begin{tabular}{|c|c|c|c|c|}
\hline Lockdown $R_{0}$ & $\begin{array}{l}\text { Life is valued } \\
\text { with }\end{array}$ & $\begin{array}{l}\text { Incremental cost } \\
\text { of lockdown }\end{array}$ & $\begin{array}{l}\text { Optimal } \\
\text { lockdown } \\
\text { duration }\end{array}$ & $\begin{array}{l}\text { Net savings relative to } \\
\text { no-lockdown baseline } \\
(\$, \text { billion })\end{array}$ \\
\hline \multirow[t]{4}{*}{0.933} & \multirow[t]{2}{*}{ VSL } & $\$ 36.93$ bil. & 8 weeks & $\$ 2,234.08$ \\
\hline & & $\$ 46.16$ bil. & 8 weeks & $\$ 2,169.45$ \\
\hline & \multirow[t]{2}{*}{ dQALY } & $\$ 36.93$ bil. & 5 weeks & $\$ 477.71$ \\
\hline & & $\$ 46.16$ bil. & 5 weeks & $\$ 431.54$ \\
\hline \multirow[t]{4}{*}{1.166} & \multirow[t]{2}{*}{ VSL } & $\$ 36.93$ bil. & 8 weeks & $\$ 2,057.64$ \\
\hline & & $\$ 46.16$ bil. & 8 weeks & $\$ 1,983.78$ \\
\hline & \multirow[t]{2}{*}{ dQALY } & $\$ 36.93$ bil. & 6 weeks & $\$ 411.61$ \\
\hline & & $\$ 46.16$ bil. & 5 weeks & $\$ 357.78$ \\
\hline
\end{tabular}

SOURCES Author's calculations

NOTES This table presents the optimal lockdown duration as a function of the assumptions listed in the table, estimated for the U.K. variant of the SARS-CoV-2 virus. The right-hand column presents the incremental net savings of a lockdown of optimal length calculated as its benefits minus the associated costs incurred over the lockdown duration

Table 4 reports the optimal lockdown duration and the associated net savings. With the U.K. variant, I find that the lockdown should be optimally extended by four weeks, from four to eight weeks, when VSL is used to value life and from two to five or six weeks, depending on the specification, when dQALY is used to value life. Under all eight sets of assumptions considered here, the estimated net savings are now substantially higher than for the currently prevailing SARS-CoV-2 variant because the higher virus contagiousness leads to more infections and deaths going forward, and a lockdown creates more value by greatly reducing the number of new infections from which future infections will propagate. Under the baseline set of assumptions described in the first row of the table, the net savings derived from an optimal lockdown increase more than three-fold from $\$ 653$ billion to $\$ 2.2$ trillion.

\section{Limitations}

I use a number of parameters reported in the COVID literature as inputs into my analysis, such as the magnitude of under-reporting, the fraction of asymptomatic cases, the hospitalization rate, and the infection fatality ratio (IFR). Therefore, I would like to caveat the findings by pointing out that these inputs may be imprecisely estimated. For example, robustness analyses show that the optimal lockdown duration may be shorter if the IFR is lower. If the speed of vaccinations is slower than what I assume, or if vaccinations do not prioritize the older population, the optimal lockdown duration may be longer. Additionally, early evidence is emerging on the late sequelae of COVID-19. ${ }^{32}$ If the long-term consequences of COVID are severe enough to result in large medical expenses, productivity losses, and shortened life spans, the optimal lockdown duration should be longer than estimated in order to help further decrease the number of new infections. ${ }^{33}$

\footnotetext{
${ }^{32}$ See, e.g., https://www.cdc.gov/coronavirus/2019-ncov/hcp/clinical-care/late-sequelae.html.

${ }^{33}$ Cutler and Summers (2020) estimate that long-term health impairments may reduce quality-adjusted life expectancy of COVID survivors by $35 \%$.
} 
Another critical parameter is the reduction in $R_{0}$ that can be achieved with a national lockdown. I rely on estimates obtained from studies of the Spring 2020 European lockdowns, which may not be perfectly applicable to the United States. In the sensitivity analyses, I consider a more conservative assumption.

The incremental costs that a lockdown would impose on the economy may be imprecisely estimated. I run sensitivity tests using a more conservative cost estimate and still find that a lockdown would be beneficial, albeit with a shorter optimal length in some specifications. It is also possible that the incremental costs to the economy may be increasing with each subsequent week of a lockdown, perhaps through the higher likelihood of bankruptcies and the associated dead-weight losses. In that case, the optimal lockdown duration may be shorter than estimated.

New literature has emerged on the non-economic costs and benefits of a lockdown, such as its impact on crime, air pollution, mental health, etc. Overall, this literature finds a number of positive or ambiguous incremental effects. Presently, due to the lack of precise estimates, it is unclear how to assign a monetary value to these incremental effects. However, if those were taken into consideration, they may point to a lower cost of a lockdown than what is currently estimated purely on the basis of reduction in economic activity.

\section{Conclusion}

To my knowledge, this paper is the first attempt to examine whether it is beneficial for the United States to follow the lead of a number of European countries and order a national lockdown and to estimate its optimal duration while explicitly modeling the effect of the ongoing vaccination program. I find that even with vaccinations a lockdown will generate significant net benefits and that it should optimally last four weeks.

A lockdown is shown to be optimal under a wide range of assumptions and parameter values. When I use a more conservative approach to valuing lives, using discounted qualityadjusted life-years that assign significantly lower values to the lives of older individuals, I find that a lockdown is still beneficial but that its optimal duration decreases to two weeks. When I consider more conservative assumptions for the lockdown effectiveness, its incremental cost to the economy, and IFR, I still find that a lockdown would be optimal, albeit at a shorter duration in some specifications.

Additionally, I evaluate two hypothetical scenarios. First, I examine the proposal that the vaccination program should administer only one dose of the vaccine, which would render vaccines less effective than two doses but would cover the population more quickly. This vaccination plan will leave the more vulnerable older population less protected from the virus, and a lockdown would save even more lives. Second, I model a hypothetical scenario in which the more contagious U.K. variant of the virus becomes predominant in the U.S. With the higher transmissibility of this variant, a lockdown would be substantially more valuable than for the currently prevailing variant; its optimal duration will lengthen by up to four weeks and the associated net savings will more than triple.

The benefits associated with a lockdown are likely to be larger than what is estimated in the paper. Evidence continues to emerge that COVID infections may lead to serious long-term complications, which may impose additional costs that should be added to the estimated cost of the pandemic. Therefore, preventing more future infections through a lockdown before the vaccination target is reached creates more value. Moreover, the cost of a lockdown may be lower than what is assumed in the paper. The literature on the Spring 2020 lockdowns documents a range of positive effects on public health and well-being, 
such as reduced traffic accidents, lower pollution, and lower mortality due to influenza and pneumonia. While the impact on domestic violence and mental health may be negative, the overall effect is likely positive. The higher benefits and lower incremental costs may point to a potentially longer optimal lockdown duration.

Despite the obvious benefits, there is widespread reluctance to impose further restrictions on mobility and economic activity in the United States; COVID presents a low threat to the young and healthy but a high threat to the elderly and those with underlying health conditions. And while a lockdown may not benefit each individual it will benefit society as a whole, as the analysis in this paper shows.

\section{Appendix: "Could the United States benefit from a lockdown? A cost-benefit analysis"}

Table 5 Summary of variables, sources, and assumptions used in the paper

COVID basic reproduction number with social distancing measures currently in place, $R_{0}(1.75)$. Sources: (Morley et al. 2020) for the COVID reproduction number as a function of reduced mobility and (Archer et al. 2020), (Pishue 2020), and Google's COVID-19 Community Mobility Report for mobility reduction estimates for the United States.

COVID effective reproduction number, $\boldsymbol{R}_{\boldsymbol{t}}(\mathbf{1 . 0 4 )}$. Source: website rt.live and author's calculations.

COVID basic reproduction number with a national lockdown (0.62). Source: (Jarvis et al. 2020). A $25 \%$ higher estimate, 0.775 , is used in sensitivity analyses.

COVID case under-reporting (true number of COVID cases is 7.7 times higher than official statistics). Source: (Reese et al. 2020).

Number of COVID cases. Source: CDC COVID Data Tracker, adjusted for under-reporting.

Vaccination. Vaccination involves two vaccine doses, administered three weeks apart. The effectiveness of the first dose is $52 \%$ and it rises to $95 \%$ after the second dose. The goal of the program is to vaccinated $70 \%$ of the U.S. population. A total of 33,878,254 vaccine doses were distributed by February 4, 2021, after which 10.5 million doses will be administered weekly. Vaccination priority goes from older to younger population groups. Due to the inability to determine who has already recovered from COVID, vaccinations include recovered individuals as well.

Fraction of asymptomatic cases (40\%). Source: CDC "COVID-19 Pandemic Planning Scenarios," Scenario 5: "Current Best Estimate."

Medical costs and outcomes (as reported in Table 1). Sources: For hospitalization risks: (Reese et al. 2020), Table 1, with missing age bins augmented by CDC's estimates on relative hospitalization risks by age (https://www.cdc.gov/coronavirus/2019-ncov/covid-data/investigations-discovery/ hospitalization-death-by-age.html), with all estimates multiplied by 0.32 to adjust for hospital and overall case under-reporting per (Reese et al. 2020); for IFR: (Levin et al. 2020) and the CDC "COVID-19 Pandemic Planning Scenarios," Scenario 5: "Current Best Estimate." A 25\% lower IFR estimate for each age bin is used in sensitivity analyses. For high- and low-risk probabilities and cost estimates: (Molinari et al. 2007) and (CEA 2019), Table 2.

VSL (as reported in Table 1). Sources: (Aldy and Viscusi 2008) and (CEA 2019).

dQALY (as reported in Table 2). Sources: (Nyman et al. 2007) for QOL weights, National Vital Statistics Reports for life expectancy by age, 3\% discount rate, \$150,000 value per QALY, author's calculations.

Incremental cost of a lockdown (\$36.93 billion per week). Source: average estimate from (OECD 2020), (Scherbina 2020), and (Barrot et al. 2020). A 25\% higher estimate, $\$ 46.16$ billion per week, is used in sensitivity analyses. 
Table 6 Sensitivity of the optimal lockdown duration to alternative assumptions, with IFR reduced by $25 \%$ Assumptions

\begin{tabular}{|c|c|c|c|c|}
\hline Lockdown $R_{0}$ & $\begin{array}{l}\text { Life is valued } \\
\text { with }\end{array}$ & $\begin{array}{l}\text { Incremental cost } \\
\text { of lockdown }\end{array}$ & $\begin{array}{l}\text { Optimal } \\
\text { lockdown } \\
\text { duration }\end{array}$ & $\begin{array}{l}\text { Net savings relative to } \\
\text { no-lockdown baseline } \\
(\$, \text { billion })\end{array}$ \\
\hline \multirow[t]{4}{*}{0.620} & \multirow[t]{2}{*}{ VSL } & $\$ 36.93$ bil. & 3 weeks & $\$ 464.51$ \\
\hline & & $\$ 46.16$ bil. & 2 weeks & $\$ 409.20$ \\
\hline & \multirow[t]{2}{*}{ dQALY } & $\$ 36.93$ bil. & 2 weeks & $\$ 76.36$ \\
\hline & & $\$ 46.16$ bil. & 1 week & $\$ 44.53$ \\
\hline \multirow[t]{4}{*}{0.775} & \multirow[t]{2}{*}{ VSL } & $\$ 36.93$ bil. & 3 weeks & $\$ 401.64$ \\
\hline & & $\$ 46.16$ bil. & 2 weeks & $\$ 341.88$ \\
\hline & \multirow[t]{2}{*}{ dQALY } & $\$ 36.93$ bil. & 2 weeks & $\$ 56.19$ \\
\hline & & $\$ 46.16$ bil. & 1 week & $\$ 31.24$ \\
\hline
\end{tabular}

SOURCES Author's calculations

NOTES This table is an update of Table 3 in the main text based on the assumption that IFR for each age bin is reduced by $25 \%$. It reports the optimal lockdown duration as a function of assumptions listed in the table. The right-hand column presents the incremental net savings of a lockdown of optimal length calculated as its benefits minus the associated costs incurred over the lockdown duration

Table 7 Sensitivity of the optimal lockdown duration to alternative assumptions, assuming that only a one vaccine dose is administered during the vaccination program

\begin{tabular}{|c|c|c|c|c|}
\hline \multicolumn{3}{|l|}{ Assumptions } & \multirow[b]{2}{*}{$\begin{array}{l}\text { Optimal } \\
\text { lockdown } \\
\text { duration }\end{array}$} & \multirow[b]{2}{*}{$\begin{array}{l}\text { Net savings relative to } \\
\text { no-lockdown baseline } \\
(\$, \text { billion })\end{array}$} \\
\hline Lockdown $R_{0}$ & $\begin{array}{l}\text { Life is valued } \\
\text { with }\end{array}$ & $\begin{array}{l}\text { Incremental cost } \\
\text { of lockdown }\end{array}$ & & \\
\hline \multirow[t]{4}{*}{0.620} & VSL & $\$ 36.93$ bil. & 4 weeks & $\$ 954.92$ \\
\hline & & $\$ 46.16$ bil. & 4 weeks & $\$ 918.00$ \\
\hline & dQALY & $\$ 36.93$ bil. & 2 weeks & $\$ 162.98$ \\
\hline & & $\$ 46.16$ bil. & 2 weeks & $\$ 144.51$ \\
\hline \multirow[t]{4}{*}{0.775} & VSL & $\$ 36.93$ bil. & 4 weeks & $\$ 851.53$ \\
\hline & & $\$ 46.16$ bil. & 4 weeks & $\$ 814.60$ \\
\hline & dQALY & $\$ 36.93$ bil. & 2 weeks & $\$ 131.24$ \\
\hline & & $\$ 46.16$ bil. & 2 weeks & $\$ 112.77$ \\
\hline
\end{tabular}

SOURCES Author's calculations

NOTES This table reports the optimal lockdown duration as a function of assumptions listed in the table, assuming that the vaccination policy is to administer only one vaccine dose. The right-hand column presents the incremental net savings of a lockdown of optimal length calculated as its benefits minus the associated costs incurred over the lockdown duration 
Availability of Data and Material All data used in this paper are publicly available, data sources are described in the paper.

Code Availability Available upon request.

\title{
Declarations
}

\author{
Competing interests None.
}

\section{Conflict of Interests None.}

\section{References}

Aldy J, Viscusi W (2008) Adjusting the value of a statistical life for age and cohort effects. Review of Economics and Statistics 90(3):573-581

Archer CL, Cervone G, Golbazi M, Fahel NA, Hultquist C (2020) Changes in air quality and human mobility in the usa during the covid-19 pandemic. Bulletin of Atmospheric Science and Technology

Arias E, Xu J (2020) National vital statistics reports. United States Life Tables, 2018

Barrot J-N, Grassi B, Sauvagnat J (2020) Costs and benefits of closing businesses in a pandemic. Working paper

Boehmer TK, DeVies J, Caruso E, van Santen KL, Tang S, Black CL, Hartnett KP, Kite-Powell A, Dietz S, Lozier M, Gundlapalli AV (2020) Changing age distribution of the covid-19 pandemic — united states, may-august 2020. Morbidity and mortality weekly report. US Department of Health and Human Services/Centers for Disease Control and Prevention 69(39)

Buitrago-Garcia D, Egli-Gany D, Counotte MJ, Hossmann S, Imeri H, Ipekci AM, Salanti G, Low N (2020) Occurrence and transmission potential of asymptomatic and presymptomatic sars-cov-2 infections: a living systematic review and meta-analysis. PLoS Med 17(9):1-25

Bullinger LR, Carr JB, Packham A (2020) Covid-19 and crime: Effects of stay-at-home orders on domestic violence. NBER Working paper

CEA (2019) Mitigating the impact of pandemic influenza through vaccine innovation https://www.white house.gov/wp-content/uploads/2019/09/Mitigating-the-Impact-of-Pandemic-Influenza-through-VaccineInnovation.pdf. Council of Economic Advisers, White House

Chen S, Igan D, Pierri N, Presbitero AF (2020) Tracking the economic impact of covid-19 and mitigation policies in europe and the united states. Covid Economics 36:1-24

Courtemanche C, Garuccio J, Le A, Pinkston J, Yelowitz A (2020) Strong social distancing measures in the United States reduced the covid-19 growth rate. Health Aff 39(7):1237-1246

Cutler DM, Summers LH (2020) The covid-19 pandemic and the \$16 trillion virus. JAMA 324(15):14951496

ECDC (2021) Risk related to the spread of new SARS-CoV-2 variants of concern in the EU/EEA - first update, https://www.ecdc.europa.eu/sites/default/files/documents/COVID-19-risk-related-to-spread-of-new-SARSCoV-2-variants-EU-EEA-first-update.pdf. European Centre for Disease Prevention and Control

Faust JS, Shah SB, Du C, Li S-X, Lin Z, Krumholz HM (2020) Suicide deaths during the stay-at-home advisory in massachusetts. medRxiv

Flaxman S, Mishra S, Gandy A, Unwin HJT, Mellan TA, Coupland H, Whittaker C, Zhu H, Berah T, Eaton JW, Monod M, Team ICC-R, Ghani AC, Donnelly CA, Riley S, Vollmer MAC, Ferguson NM, Okell LC, Bhatt S (2020) Estimating the effects of non-pharmaceutical interventions on covid-19 in europe. Nature 584:257-261

Gallup G, Newport F (1991) Mirror of america: Fear of dying. Gallup Poll News Services

Gold MR, Stevenson D, Fryback DG (2002) Halys and qalys and dalys, oh my: Similarities and differences in summary measures of population health. Annual Review of Public Health 23(1):115-134. PMID: 11910057

Hubbell BJ (2006) Implementing qalys in the analysis of air pollution regulations. Environmental \& Resource Economics 34:365-384

IMF (2020) World Economic Outlook, Chapter 2, "The Great Lockdown: Dissecting the Economic Effects," October 2020. International Monetary Fund 
Jarvis CI, van Zandvoort K, Gimma A, Prem K, nCov working group C, Klepac P, Rubin GJ, Edmunds WJ (2020) Quantifying the impact of physical distance measures on the transmission of covid-19 in the uk. medRxiv

Kung S, Doppen M, Black M, Hills T, Kearns N (2020) Assessing the age specificity of infection fatality rates for covid-19: systematic review, meta-analysis, and public policy implications. Lancet

Leslie E, Wilson R (2020) Sheltering in place and domestic violence: Evidence from calls for service during covid-19. Journal of Public Economics. Forthcoming

Levin AT, Hanage WP, Owusu-Boaitey N, Cochran KB, Walsh SP, Meyerowitz-Katz G (2020) Assessing the age specificity of infection fatality rates for covid-19: systematic review, meta-analysis, and public policy implications. European Journal of Epidemiology

Mizumoto K, Kagaya K, Zarebski A, Chowell G (2020) Estimating the asymptomatic proportion of coronavirus disease 2019 (covid-19) cases on board the diamond princess cruise ship, available at https://doi.org/10.2807/1560-7917.ES.2020.25.10.2000180. Euro Surveill 10(25):2000180

Molinari N, Ortega-Sanchez I, Messonnier M, Thompson W, Wortley P et al (2007) And The annual impact of seasonal influenza in the u.s.: Measuring disease burden and costs. Vaccine 25(27):5086-96

Morley CP, Anderson KB, Shaw J, Stewart T, Thomas SJ, Wang D (2020) Social distancing metrics and estimates of sars-cov-2 transmission rates: Associations between mobile telephone data tracking and $\mathrm{r}$. Journal of Public Health Management and Practice 26(6):606-612

Neumann PJ, Greenberg D (2009) Is the United States ready for qalys? Health Aff 24(5):1366-1371

Nyman JA, Barleen NA, Dowd BE, Russell DW, Coons SJ, Sullivan PW (2007) Quality-of-life weights for the us population: self-reported health status and priority health conditions, by demographic characteristics. Med Care 45:618-628

OECD (2020) Evaluating the Initial Impact of COVID Containment Measures on Activity, June 10, 2020. https://read.oecd-ilibrary.org/view/?ref=126_126496-evgsi2gmqj\&title=Evaluating_the initial_impact_of_COVID-19_containment_measures_on_economic_activity. Organization for Economic Co-operation and Development

Oran DP, Topol EJ (2020) Prevalence of asymptomatic sars-cov-2 infection : a narrative review. Ann Intern Med 173(5):362-367

Pepe E, Bajardi P, Gauvin L, Privitera F, Lake B, Cattuto C, Tizzoni M (2020) Covid-19 outbreak response, a dataset to assess mobility changes in Italy following national lockdown. Scientific Data 7(230):1-7

Pieh C, Budimir S, Delgadillo J, Barkham M, Fontaine JRJ, Probst T (2020) Mental health during covid-19 lockdown in the united kingdom. Psychosomatic Medicine

Pishue B (2020) COVID-19'S impact on freight: an analysis of long-haul freight movement during a pandemic. Technical report, INRIX Research Report

Pliskin JS, Shepard DS, Weinstein MC (1980) Utility functions for life years and health status. Oper Res 28(1):206-224

Polack FP, Thomas SJ, Kitchin N, Absalon J, Gurtman A, Lockhart S, Perez JL, Marc GP, Moreira ED, Zerbini C, Bailey R, Swanson KA (2020) Safety and efficacy of the bnt162b2 mrna covid-19 vaccine. The New England Journal of Medicine 383:2603-2615

Prieto L, Sacristán JA (2003) Problems and solutions in calculating quality-adjusted life years (qalys). Health and Quality of Life Outcomes 1(80):1366-1371

Reese H, Iuliano AD, Patel NN, Garg S, Kim L, Silk BJ, Hall AJ, Fry A, Reed C (2020) Estimated incidence of covid-19 illness and hospitalization - united states. Clinical Infectious Diseases

Salje H, Kiem CT, Lefrancq N, Courtejoie N, Bosetti P, Paireau J, Andronico A, Hozé N., Richet J, Dubost C-L, Strat YL, Lessler J, Levy-Bruhl D, Fontanet A, Opatowski L, Boelle P.-Y., Cauchemez S (2020) Estimating the burden of sars-cov-2 in france. Science 369(6500):208-211

Sassi F (2006) Calculating qalys, comparing qaly and daly calculations. Health Policy and Planning 21:402_ 408

Scherbina A (2020) Determining the optimal duration of the covid-19 suppression policy: A cost-benefit analysis. Working paper

Shilling F, Waetjen D (2020) Impact of COVID19 mitigation on california traffic crashes. https:// roadecology.ucdavis.edu/files/content/projects/COVID_CHIPs_Impacts_updated_415_0.pdf. UC Davis

Song HJ, Lee E-K (2018) Evaluation of willingness to pay per quality-adjusted life year for a cure. a contingent valuation method using a scenario-based survey. Medicine 97(38):1-10

Tumpey AJ, Daigle D, Nowak G (2018) Communicating during an outbreak or public health investigation, https://www.cdc.gov/eis/field-epi-manual/chapters/Communicating-Investigation.html. Centers for Disease Control and Prevention

UNODC (2020) Effect of the COVID-19 pandemic and related restrictions on homicide and property crime. United Nations Office on Drugs and Crime 
Venter ZS, Aunan K, Chowdhury S, Lelieveld J (2020) Air pollution declines during covid-19 lockdowns mitigate the global health burden. Environ Research

Publisher's Note Springer Nature remains neutral with regard to jurisdictional claims in published maps and institutional affiliations.

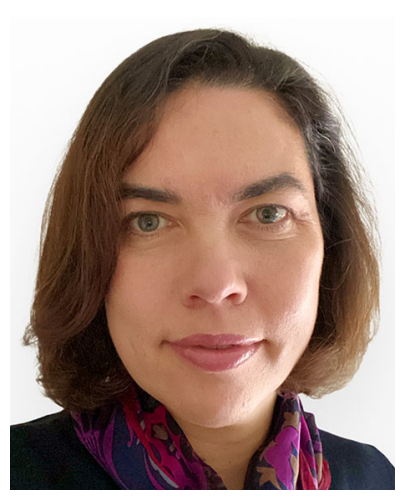

Anna Scherbina is an associate professor of finance at Brandeis University. Prior to joining Brandeis University, she was an associate professor at UC Davis and an assistant professor at the Harvard Business School. From 2017 to 2019 she worked as a senior economist at the White House's Council of Economic Advisers covering a variety of topics, including finance, fintech, cybersecurity, biothreats, AI and semiconductor policy, and foreign investment in the United States. She also worked at the Federal Reserve Board and the International Monetary Fund. 